To link to this article / Para enlazar con este artículo:

https://doi.org/10.14198/fem.2020.35.11

To cite this article / Para citar este artículo:

Merlyn, Marie-France. «Dime lo que escuchas y te diré quién eres. Representaciones de la mujer en las 100 canciones de reggaetón más populares en 2018». En Feminismo/s, 35 (junio 2020): 291-320. DOI: 10.14198/fem.2020.35.11

\title{
DIME LO QUE ESCUCHAS Y TE DIRÉ QUIÉN ERES. REPRESENTACIONES DE LA MUJER EN LAS 100 CANCIONES DE REGGAETÓN MÁS POPULARES EN 2018
}

\author{
TELL ME WHAT YOU LISTEN TO AND I WILL TELL YOU \\ WHO YOU ARE. REPRESENTING WOMEN IN 100 OF THE \\ MORE POPULAR REGGAETON SONGS IN 2018
}

\author{
Marie-France MERLYN \\ Pontificia Universidad Católica del Ecuador, Quito \\ MFMERLYNS@puce.edu.ec \\ orcid.org/0000-0001-6171-2691
}

\section{Resumen}

El propósito del presente trabajo es analizar y caracterizar el rol de la mujer en las representaciones de los vídeos, letras y lugar de las intérpretes dentro del reggaetón. Se analizan 100 vídeos y letras de canciones más populares en 2018; se utiliza para el análisis de los vídeos la observación detallada con registro y para las letras el análisis temático, que consta de seis fases: familiarización con los datos, generación de categorías o códigos iniciales, búsqueda de temas, revisión de temas, definición y denominación de temas e informe final. Los resultados evidencian que la mujer en estas canciones es sexualizada, objetivada, descrita a través de modelos relacionales tradicionales y negativos, lo que convierte el reggaetón en un espacio que transmite principalmente el modelo de la identidad del disfrute.

Palabras clave: reggaetón; mujer; identidad; modelos; representaciones. 
Dime lo que escuchas y te diré quién eres. Representaciones de la mujer en las 100 canciones de reggaetón más populares en 2018

\begin{abstract}
The purpose of this work is to analyze and characterize the role of women in the representations in the videos, lyrics, and the place of the women performers within the reggaeton rhythm. One hundred videos and lyrics of most popular songs in 2018 are analyzed; the detailed observation with registration is used for the analysis of the videos and for the lyrics the thematic analysis is used, which consists of 6 phases: familiarization with the data, generation of categories or initial codes, search of topics, review of topics, definition and denomination of topics and final report. The results show that women are sexualized, objectified, described through traditional and negative relational models, which makes reggaeton a space in which the model of the identity of enjoyment is transmitted.
\end{abstract}

Keywords: Reggaeton; Woman; Identity; Models; Representations.

\title{
1. INTRODUCCIÓN
}

La música, más allá de ser un arte, es una expresión cultural dependiente del contexto histórico, geográfico y social. Además, es un potente medio de comunicación, a través del cual un individuo o un grupo puede llegar con su mensaje a miles de receptores; a diferencia de otros medios, la música está presente sin ningún tipo de censura en espacios públicos como restaurantes, buses, centros comerciales, vía pública, etc.

Si bien las melodías pueden ser únicamente instrumentales, en los últimos dos siglos se han popularizado aquellas con letras, y desde los años 80 del siglo anterior, se acompañan con vídeos. La música per se no transmite un mensaje en particular, el mensaje es dado por las letras y las imágenes que se le asocian (Vernallis 16). Para Sedeño, el vídeo es el mensaje «más definidor de la cultura posmoderna», ya que posee una variedad formal y narrativa cercana a la de la publicidad (2-3). Según el Informe del Task Force on the Sexualization of Popular Music (TFSPM 9), la primera investigación sobre los contenidos de las canciones se realizó en 1969, y desde entonces muchos se han interesado en el análisis de contenidos y vídeos de tipo sexual en las canciones, así como de su impacto en los individuos. Sus resultados evidenciaron que la música es el medio de comunicación que más contenidos sexuales incluye comparado con otros (TFSPM 10). Un análisis por décadas (entre 1959 y 2009) del Top-100 en USA muestra que el aumento de la

Feminismo/s 35, junio 2020, pp. 291-320 
sexualización en la música ocurrió entre 1990 y 2000 (Hall, West y Hill 111), con un incremento de casi tres veces de los contenidos sexuales en las canciones de intérpretes masculinos (pasando del $11.1 \%$ al $32.1 \%$ ) y apareciendo en las canciones de intérpretes femeninas (del $0 \%$ al 14.3\%).

El impacto que tienen los contenidos sexuales de las canciones es analizado en el Informe (TFSPM 3-4), donde se evidencia que la música sexualizada influye en las actitudes y conductas de manera negativa, aunque existen algunas investigaciones que llegan a resultados contrarios en este aspecto (Sprankle, End y Bretz 36). El Informe de la TFSPM (6-7) se refiere esencialmente a la música en lengua inglesa escuchada en los Estados Unidos y Australia, en donde los géneros musicales con mayor sexualización son el rap, pop, hip hop y soul.

América Latina no escapa de esta tendencia sexualizadora de la música y sus géneros se imponen a nivel mundial. Así, en 2018, del Top-10 de las canciones más escuchadas en YouTube ocho fueron latinas, de estas, seis pertenecieron al género reggaetón (Unidad Editorial Información Deportiva). Si bien América Latina posee varios géneros musicales propios (salsa, cumbia, merengue, bossa nova, música andina, etc.), lo que se vuelve popular obedece a las mismas leyes de globalización y mercado que regulan lo que se produce y se escucha a nivel mundial. La tendencia global indica que lo más escuchado en español es reggaetón. En Ecuador este ritmo es aún más popular, ya que entre las 10 más escuchadas del 2018, 9 pertenecieron a este género (Redacción El Comercio).

El reggaetón surgió en las barriadas de Puerto Rico en los años 80. Otros ritmos como la salsa habían entrado en crisis, permitiendo el surgimiento de un género que en un inicio circuló de manera encubierta («underground»), expresando temas populares y marginales sin restricción alguna (Rodríguez Rivera 27-29). Censurado inicialmente por sus contenidos, desafiantes de la moral y el orden político, la popularidad y el éxito comercial hicieron que poco a poco se insertara en la cultura del país; el reggaetón «era real» y «hacía referencia a las condiciones sociales del país: tasas de desempleo de hasta $65 \%$ en algunas zonas, escuelas descalabradas, corrupción gubernamental y una violencia rampante vinculada al narcotráfico» (Negrón-Muntaner y Rivera 33). Los intentos de censura lo hicieron más popular, ya que las canciones con letras más depuradas lograron difundirse mejor. Paulatinamente

Feminismo/s 35, junio 2020, pp. 291-320 
se abrió al mercado, combinándose con ritmos como el rap y adquiriendo un tinte más comercial, perdiendo el carácter contestatario inicial (Rodríguez Rivera 28-29). En los años noventa, agotada esta vena comercial, se mezcló con el reggae jamaiquino y regresó a sus raíces «underground» retomando los temas callejeros (violencia y sexo). El momento de auge a nivel internacional del reggaetón ocurre en el siglo XXI, con los éxitos comerciales de las canciones «Pobre Diabla» de Don Omar (2003) y «Gasolina» de Daddy Yankee (2004), que tienen letras de contenido sexual pero son menos violentas, más románticas y más cantadas (Rodrigues Morgado 33). El reggaetón entonces puede definirse como «un sanchocho de rap y reggae en español, que llegó a su punto en los barrios y caseríos de Puerto Rico» (NegrónMuntaner y Rivera 30). Finalmente, los mercados internacionales terminaron validándolo y forzando su aceptación como producto de exportación y atractivo hacia la isla (Negrón-Muntaner y Rivera 36-37). El reggaetón logra así consolidar una nueva identidad del puertorriqueño, una comunidad imaginada subalterna, basada en tres elementos fundamentales: vivencia de una sexualidad libre, reivindicación de la ilegalidad o la extralegalidad y la propuesta de una nueva ética de vida focalizada en el disfrute (drogas, sexo y alcohol) (Rodríguez Rivera 32-34). Para entender un producto cultural se debe mirar la cultura dominante, y esto es válido para otros géneros. Así, Adams y Fuller (941) señalan que la misoginia presente en las letras del rap es un producto de los valores misóginos correspondientes a la historia de la cultura norteamericana.

Sin embargo, más allá de ser el producto de grupos sociales y la expresión de las protestas de un pueblo, la música ha pasado a formar una gran Industria Cultural que genera miles de millones de dólares. Horkheimer y Adorno (165) introdujeron la noción de Industrias Culturales refiriéndose a esas instituciones que emplean modos de producción y organización de las corporaciones industriales para producir y difundir símbolos como bienes culturales; se afirma que esto aplica para la música, situándola como una Industria Cultural, al decir que «entre las industrias Culturales, la industria musical tiene un creciente mercado» y que «el consumo no solamente se refiere a las mercancías sino también a estilos y formas de vida» (Martínez Noriega 22). 
Al globalizarse, el reggaetón pasa a ser parte del mercado y a obedecer, como los otros ritmos musicales, a las leyes del consumo. Así, el género representa hoy «una de las historias más impresionantes de triunfo económico» (Negrón-Muntaner y Rivera 37). Objetivamente hablando, la exportación masiva del género hacia otros países disminuyó el interés de producir canciones con contenidos de protesta, y aumentó la producción de contenidos que «venden» mejor, como ha pasado con todos los géneros musicales. Connor (en Aguilar Barreto y Peñaloza Figueroa 111) dice que «para la música comercial lo importante es ser vista y escuchada. Existe en cuanto es visible como representación y por tanto está mediada y administrada por las estructuras y ritmos del espectáculo y del consumo que acompaña la visibilidad».

Así, lo que trasciende las fronteras ya no es reggaetón de protesta y resistencia, sino comercial, donde los contenidos relacionales y altamente sexualizados han desplazado completamente a los otros que estas canciones tenían en su origen. Actualmente, el mensaje musical no se transmite únicamente por la letra de las canciones sino también por las imágenes de los vídeos que los acompañan y hasta por la que transmiten los intérpretes con su actitud.

El mensaje que emite el reggaetón es casi único en este sentido: mantiene un énfasis en la «sexualidad libre», en la que se entretejen relaciones de género eufemísticamente definidas como «interesantes» (Rodríguez Rivera 34). Cabe destacar que la sexualidad que propone es sexista y violenta, y en ella colaboran y participan mujeres, convirtiéndose en «objeto y sujeto al mismo tiempo» (Rodríguez Rivera 35). La idea que subyace a este razonamiento es que existe un empoderamiento de la mujer dentro de su rol sexual sobre todo a través del llamado «perreo», baile asociado al reggaetón. Por su parte, Rivera (4) piensa que no hay posibilidad de acuerdo porque el espacio del perreo se maneja con las leyes del sexismo; incluso Rodríguez Rivera (34) admite la reproducción de modelos patriarcales en el reggaetón.

Con el argumento del empoderamiento de la mujer en el perreo, el reggaetón es defendido desde distintas perspectivas, entre ellas el activismo feminista (Sosa, en Feliciano 1; Sosa, en Noisey Colombia 1; Alcaraz 1-23), la lingüística (Dávila 59-65), la sociología (Negrón-Muntaner y Rivera 30-37; Rodríguez Rivera 26-37), el género (Rodrigues Morgado 38-44) y el arte

Feminismo/s 35, junio 2020, pp. 291-320 
(Caycedo, en Rivera 2-4). Sin embargo, también hay posturas de que este empoderamiento de la mujer a través de una imagen sexualizada en los medios, no es más que un nuevo «empaque» para su objetivación sexual (Levy, en Harvey y Hill 54).

Se observan dos tendencias frente a la sexualización: la que se opone y aquella a favor. Según Harvey y Hill (53-54), dentro del propio movimiento feminista se están polarizando las posturas, estableciendo dos posiciones: una que sostiene que la proliferación de representaciones de mujeres como deseables y sexuales representa un cambio positivo en la manera de ver la sexualidad femenina, mientras que otras manifiestan que estas mismas imágenes están al servicio del capitalismo de consumo patriarcal.

Harvey y Hill (54-55) proponen una nueva lectura del tema, no binaria, que trata sobre la construcción subjetiva de la persona en un contexto social dado. Retomando la noción de subjetivización sexual de Gill, las autoras suman la de la «tecnología de la sensualidad» de Radner (en Harvey y Hill 54-55) y añaden a esto los discursos del nuevo ejercicio sexual femenino, para generar una nueva noción, a través de la cual las mujeres están construyéndose, la del «emprendimiento sexual». La nueva mujer tiene que ser:

Obligatoriamente sexy y estar siempre «a la altura», al ser interpelada a través de discursos en los que el sexo es laborioso y requiere trabajo constante y reafirmación [...] La belleza, deseabilidad y el rendimiento sexual constituyen sus proyectos en curso y se la exhorta a llevar una vida sexual «condimentada» cuyos límites -entre ellos la heterosexualidad y la monogamia- se controlan estrictamente, incluso cuando se borran o desaprueban a través de discursos de juego y experimentación. (Harvey y Hill 55).

Estas consideraciones generales conducen a analizar el papel de la mujer en el reggaetón actual. El objetivo del presente estudio es analizar y caracterizar el rol de la mujer en las representaciones de los vídeos y letras, y el lugar de las mujeres en el género (intérpretes y compositoras), en las 100 canciones de reggaetón más populares del 2018, bajo el supuesto de una posible sexualización y objetivación de la mujer en sus contenidos. 


\section{METODOLOGÍA}

\subsection{Muestra}

Se escogieron 100 canciones que cumplieran con los siguientes cuatro criterios de inclusión: fecha de publicación, género reggaetón, popularidad y tener vídeo oficial ${ }^{1}$.

En cuanto a la fecha de publicación, se seleccionaron vídeos oficiales publicados en YouTube entre el 12/01 y el 21/12 de 2018 y/o clasificados en VEVO con fecha 2018. Para todos se verificó la pertenencia al reggaetón de acuerdo a: (1) estar clasificado como tal en VEVO o (2) ser citado en uno al menos de los diez primeros links de Google como reggaetón o (3) hablar de reggaetón o contener en su letra la palabra reggaetón.

El criterio de «popularidad» hizo referencia al posicionamiento en las listas de Spotify, como las más escuchadas, o propuestas como tal en YouTube en los listados o canciones referenciadas en sitios especializados de reggaetón como «las mejores». Finalmente, las canciones debían tener vídeo oficial publicado en YouTube, eliminando aquellas que tenían solo vídeos de concierto o con letras.

Los vídeos analizados han permanecido en YouTube en promedio 168 días, alcanzando un poco más de 1.200 .000 visualizaciones por vídeo por día. En relación al género de los intérpretes en la muestra, ochenta y seis canciones son interpretadas por hombres, cuatro por mujeres y en diez ambos géneros comparten el micrófono (llamamos a estas «reggaetón mixto»). En los resultados distinguiremos las canciones que provienen de cada una de las fuentes cuando sea pertinente.

\subsection{Procedimiento}

En la presente investigación se decidió hacer un análisis de la representación de la mujer en el reggaetón desde tres ejes: análisis de los vídeos, de las letras, y de la presencia femenina en el género (imagen de las intérpretes y presencia como compositoras). Las investigaciones, en general, abordan por separado

1. Por razones de espacio, no se incluye la lista total de las canciones analizadas con sus títulos e intérpretes; la muestra analizada está disponible para las personas que quieran confirmar o refutar la investigación bajo pedido al correo del autor corresponsal.

Feminismo/s 35, junio 2020, pp. 291-320 
Dime lo que escuchas y te diré quién eres. Representaciones de la mujer en las 100 canciones de reggaetón más populares en 2018

estos componentes. Así, hay algunas que se han centrado en analizar el vídeo clip (Aubrey y Frisby 482; Rodríguez-López y Caldeiro- Pedreira 65; Sedeño 4); otras han puesto el énfasis en el análisis del contenido de las letras (Adams y Fuller 950); algunas han considerado como opción analizar el contenido de vídeos producidos por mujeres (Pérez-Rufí 206); algunas analizan no solo a la mujer representada, sino a las intérpretes también (Aubrey y Frisby 482; Pérez-Rufí 216; Rodríguez-López y Caldeiro-Pedreira 67-77), y en otros se analiza a los intérpretes masculinos (Aubrey y Frisby 483; Sedeño 8). El presente estudio contempla simultáneamente varios parámetros para el análisis.

\subsubsection{Vídeos}

La metodología empleada en el análisis de los vídeos fue la observación detallada con registro en una matriz de la presencia/ausencia de las categorías creadas para el análisis (tabla 1).

Tabla 1: Categorías de codificación de las imágenes

\begin{tabular}{|l|l|}
\hline Información general & - Nombre de la canción. \\
& - Nombre del/la/los intérpretes. \\
& - Fecha de publicación en la web. \\
& - Género del/la/los intérpretes. \\
& - Compositores/as. \\
\hline $\begin{array}{l}\text { Tipo de baile } \\
\text { representado }\end{array}$ & - Baile provocador: baile con movimientos pélvicos y \\
& sugerentes sin pareja. \\
& - Perreo: movimientos pélvicos en posturas de perreo \\
& solas o acompañadas. \\
& - Perreo «duro» o marroneo: imitación de actos sexuales \\
& de manera casi pornográfica pero con ropa. \\
& - Otro tipo de baile: grupal/ coreográfico \\
& - No baile: ausencia de baile femenino en el vídeo \\
\hline Presentación de las & - En ropa corta o pegada. \\
mujeres & - En ropa interior. \\
& - En terno de baño. \\
& - Desnudos femeninos (parcial o total). \\
& - Vestida/vídeo sin mujer. \\
\hline
\end{tabular}

Feminismo/s 35, junio 2020, pp. 291-320 
Dime lo que escuchas y te diré quién eres. Representaciones de la mujer en las 100 canciones de reggaetón más populares en 2018

\begin{tabular}{|c|c|}
\hline Objetivación de la mujer & $\begin{array}{l}\text { - Fragmentada: enfoques de cámara en senos, nalgas, } \\
\text { pelvis. } \\
\text { - Ornamental: número de mujeres sobrerrepresentadas en } \\
\text { relación a varones, adornando o rellenado las escenas } \\
\text { (intercambiables y anónimas). } \\
\text { - No objetivada: mujer presentada como protagonista } \\
\text { principal de una historia no sexual, sin enfoques } \\
\text { fragmentados al cuerpo }\end{array}$ \\
\hline Mujer sexualizada & $\begin{array}{l}\text { - Provocativa: bocas abiertas con lenguas, piernas } \\
\text { abiertas al sentarse, lamiendo objetos, moviéndose } \\
\text { explícitamente paradas o sentadas. } \\
\text { - Lasciva: acariciándose lascivamente. } \\
\text { - Del goce: parejas o grupos de mujeres en poses sexuales } \\
\text { o interactuando sexualmente. } \\
\text { - No sexualizada: mujer presentada en todo el vídeo en } \\
\text { interacciones no sexuales ni seductoras }\end{array}$ \\
\hline $\begin{array}{l}\text { Tipo de ambiente } \\
\text { representado }\end{array}$ & $\begin{array}{l}\text { - Sexualizados: Nocturno de fiesta con alusiones eróticas/ } \\
\text { Diurno de diversión con alusiones eróticas (playas, } \\
\text { piscinas, canchas, etc.)/ Sexual (prostíbulos, clubes } \\
\text { de striptease, palos de pole dance) / Íntimo (camas, } \\
\text { duchas, bañeras). } \\
\text { - No sexualizados: Calle, barrio popular (urbano) } \\
\text { / Aparcamientos, subterráneos, callejones, autos / } \\
\text { Estudio de grabación / Escenarios de películas (vídeos } \\
\text { narrativos) /Mansiones y castillos } \\
\text { - Otros ambientes: aeródromos, hangares, hoteles, jardín, } \\
\text { teatro, etc. }\end{array}$ \\
\hline $\begin{array}{l}\text { Sexualización del } \\
\text { ambiente }\end{array}$ & $\begin{array}{l}\text { - Besos, caricias, contacto corporal. } \\
\text { - Imitación de posturas, escenas íntimas. } \\
\text { - Caricias explícitamente sexuales o acto sexual. }\end{array}$ \\
\hline Consumo de sustancias & $\begin{array}{l}\text { - Alcohol. } \\
\text { - Cigarrillo/vaporizadores/pipas. } \\
\text { - Pastillas. } \\
\text { - No consumo }\end{array}$ \\
\hline
\end{tabular}

Fuente: elaboración propia (2019)

\subsubsection{Letras}

Para el estudio del contenido de las canciones, se utilizó el método de análisis temático de Braun y Clarke (87), que consta de 6 fases: (1) familiarización con los datos, (2) generación de categorías o códigos iniciales, (3) búsqueda

Feminismo/s 35, junio 2020, pp. 291-320 
de temas, (4) revisión de temas, (5) definición y denominación de temas y (6) informe final.

En la fase 1, las letras de las canciones interpretadas por hombres, mujeres y mixtas, fueron retomadas en tres documentos diferenciados; se completaron las palabras incompletas para facilitar la lectura (ej.: pa', vamo', e', ere', entre otras), se buscó en la Internet el significado de palabras desconocidas, que correspondían al léxico caribeño y propias de reggaetón. En esta primera familiarización se identificaron temáticas generales, que fueron una guía para las fases 2 y 3 .

Las fases 2 (generación de códigos iniciales) y 3 (búsqueda de temas) fueron realizadas con el procesador cualitativo Nvivo; se realizó una codificación inductiva de la información, reagrupando aquella que tenía un mismo significado, a la vez que se buscaron temas generales por prevalencia en el discurso de palabras y narraciones similares.

En la fase 4, se revisó y reorganizó la información en categorías más inclusivas. Así mismo, se generaron tres nuevas categorías. En la fase 5, se definieron y denominaron los temas definitivos, que fueron los siguientes: Representaciones del hombre y de la mujer, Relaciones de Pareja, Ruptura, Sexo, Sexualidad, Ambiente.

Se debe recalcar que en la codificación no se eliminaron las repeticiones de un mismo estribillo o parte de la canción. Se considera importante dejar la letra en su totalidad y codificarla enteramente puesto que, a nivel cognitivo, la repetición garantiza la memorización de un mensaje.

\section{RESULTADOS}

Los resultados expuestos se refieren principalmente a las representaciones de la mujer; no se expondrán ni analizarán resultados referentes a las otras categorías.

Las descripciones de la mujer serán expuestas y analizadas siguiendo el siguiente esquema: representaciones de la mujer en los vídeos, letras, y tipo de presencia femenina en el género (intérpretes, compositoras). 
Dime lo que escuchas y te diré quién eres. Representaciones de la mujer en las 100 canciones de reggaetón más populares en 2018

\subsection{Representaciones de las mujeres en los vídeos}

\subsubsection{Imágenes}

Las mujeres están presentes en casi la totalidad de los vídeos de reggaetón (99), generalmente con ropa corta, pegada, ropa interior, terno de baño o incluso se puede llegar a verlas parcialmente desnudas. Dos vídeos no presentan mujeres de estas maneras: en uno solo está el intérprete masculino y en otro la mujer usa un vestido de noche durante todo el vídeo (tabla 2).

Tabla 2: Categorización de las imágenes de mujeres en los vídeos analizados

\begin{tabular}{|l|c|}
\hline \multicolumn{1}{|c|}{ Presentación de mujeres } & Número de vídeos \\
\hline Ropa corta o pegada & 80 \\
\hline Ropa interior & 45 \\
\hline Terno de baño & 26 \\
\hline Desnudos femeninos & 10 \\
\hline Vestida/vídeo sin mujer & 2 \\
\hline
\end{tabular}

Fuente: elaboración propia (2019)

Cabe recalcar que en los vídeos, una categoría no excluye a otra; por el contrario, la mayoría de vídeos tienden a presentar varias simultáneamente (tabla 3).

Tabla 3: Número de categorías en un mismo vídeo

\begin{tabular}{|c|c|}
\hline $\begin{array}{c}\text { Categorías presentadas } \\
\text { en un mismo vídeo }\end{array}$ & Número \\
\hline Ninguna & 2 \\
\hline Una & 45 \\
\hline Dos & 40 \\
\hline Tres & 11 \\
\hline
\end{tabular}

Fuente: elaboración propia (2019)

Las mujeres en los vídeos del reggaetón analizados, aparte de estar presentes con estos diversos tipos de indumentarias, también se encuentran 
representadas a través de su actuar. Este actuar será expuesto como: la mujer que baila, la mujer objeto y la mujer sexual.

\subsubsection{La mujer que baila}

La mujer realiza principalmente tres tipos de baile: provocador, perreo y perreo «duro», en solitario o en algunos casos grupalmente (35 vídeos), con o sin coreografía. En algunos vídeos no hay baile de ningún tipo por parte de las mujeres, puesto que narran historias (tabla 4); cabe recalcar que varios tipos de baile pueden presentarse en un mismo vídeo.

Tabla 4: La mujer que Baila

\begin{tabular}{|l|c|}
\hline \multicolumn{1}{|c|}{ Tipo de baile } & Número de vídeos \\
\hline Baile provocador & 49 \\
\hline Perreo & 40 \\
\hline Perreo duro & 16 \\
\hline Perreo o baile grupal/coreográfico & 35 \\
\hline No baile & 35 \\
\hline
\end{tabular}

Fuente: elaboración propia (2019)

\subsubsection{La mujer objeto}

En las imágenes se observó que la mujer es objetivada, en la medida que en varias tomas es presentada como un fragmento de mujer (solo se ven lo senos, nalgas o pelvis). Por otro lado, en casi la mitad de los vídeos es presentada en sobrenúmero en relación al varón, alrededor o detrás de él, lo que la pone en el rango de un objeto ornamental, intercambiable y anónima. Sin embargo, en algunos vídeos la mujer es protagonista de una historia, generalmente romántica, y no hay enfoques de cámara fragmentados (21 vídeos) (tabla 5). De la misma manera, varias representaciones pueden estar presentes en un mismo vídeo. 
Dime lo que escuchas y te diré quién eres. Representaciones de la mujer en las 100 canciones de reggaetón más populares en 2018

Tabla 5: La mujer objetivada

\begin{tabular}{|l|c|}
\hline \multicolumn{1}{|c|}{ Tipo de objetivación } & Número de vídeos \\
\hline Fragmentada & 63 \\
\hline Ornamental & 49 \\
\hline No objetivada & 21 \\
\hline
\end{tabular}

Fuente: elaboración propia (2019)

\subsubsection{La mujer sexual}

En 70 vídeos, se presentan varios tipos de representaciones sexualizadas de la mujer: provocativas, deseosas y lujuriosas, ya sea adoptando poses que evocan el deseo o los actos sexuales, acariciándose o interactuando de manera sexual en pareja o grupos. Solo un número reducido de vídeos no sexualiza directamente a la mujer (tabla 6).

Tabla 6: La mujer sexual

\begin{tabular}{|l|c|}
\hline Tipo de sexualización & Número de vídeos \\
\hline Provocativa & 58 \\
\hline Lasciva & 48 \\
\hline Del goce & 21 \\
\hline No sexualizada & 13 \\
\hline
\end{tabular}

Fuente: elaboración propia (2019)

Estas mujeres, ademá,s se encuentran en ambientes erotizados, de fiesta o de diversión, lo que está acorde con el tipo de música, puesto que se trata de un baile movido, o en ambientes directamente sexuales o íntimos. Los ambientes sexualizados son los más representados en los vídeos analizados; ambientes no sexualizados están presentes en menor grado; entre ellos destacan los callejeros y populares. Los ambientes más representados se presentan en la tabla 7; se debe tomar en cuenta en los datos presentados a continuación que varios ambientes pueden estar presentes en un mismo vídeo. 
Dime lo que escuchas y te diré quién eres. Representaciones de la mujer en las 100 canciones de reggaetón más populares en 2018

Tabla 7: Ambientes más representados en los vídeos analizados

\begin{tabular}{|l|l|c|c|}
\hline \multicolumn{1}{|c|}{ Tipo } & \multicolumn{1}{|c|}{ Desglose } & Número & $\begin{array}{c}\text { Total } \\
\text { por tipo }\end{array}$ \\
\hline \multirow{5}{*}{ Sexualizados } & Nocturno de diversión erotizado & 34 & 94 \\
\cline { 2 - 4 } & Diurno de diversión erotizado & 24 & \\
\cline { 2 - 4 } & Íntimos & 28 & \\
\cline { 2 - 5 } & Sexuales (prostíbulos y afines) & 8 & \\
\hline \multirow{5}{*}{ No sexualizados } & $\begin{array}{l}\text { Calle, graffitis/ barrio popular/ ventas } \\
\text { callejeras }\end{array}$ & 16 & 65 \\
\cline { 2 - 5 } & $\begin{array}{l}\text { Aparcamientos/ subterráneos/ autos como } \\
\text { escenario/ callejón/ paredes }\end{array}$ & 14 & \\
\cline { 2 - 5 } & Estudio & 14 & \\
\cline { 2 - 5 } & Escenarios de película & 13 & \\
\cline { 2 - 5 } & Mansiones/castillos & 25 & 25 \\
\hline \multirow{2}{*}{ Otros } & & & \\
\hline
\end{tabular}

Fuente: elaboración propia (2019)

La sexualización del ambiente se incrementa a través de las conductas representadas relacionadas con el sexo. Así, cuarenta y cinco muestran besos, caricias y contacto corporal, veintiuna presentan imitaciones claras de posturas y escenas íntimas, y nueve exhiben caricias explícitamente sexuales o el acto sexual per se. Si a esto se suman indicadores de vestimenta de la mujer (excluyendo ropa corta o pegada), tipo de baile, tipo de objetivación, tipo de sexualización y ambientes íntimos y sexuales, solo cuatro canciones no contienen ningún indicador de sexualización.

\subsection{Descripciones de las mujeres en las letras de las canciones}

Con las categorías finales generadas se codificó el 97.04 \% de los textos de las canciones interpretadas por mujeres, el $61.64 \%$ de los textos de las interpretadas por hombres y el $88.45 \%$ de los textos de reggaetón mixto. Los resultados indican los «porcentajes de cobertura» del texto codificado, y no del texto original y total. 
Dime lo que escuchas y te diré quién eres. Representaciones de la mujer en las 100 canciones de reggaetón más populares en 2018

$\mathrm{Al}$ analizar las letras, ciertos temas surgieron como principales; de estos, las descripciones sobre el hombre y la mujer ocuparon el $26 \%$ de los textos codificados. Otros temas (no analizados en este artículo) tuvieron los siguientes porcentajes de cobertura: Relaciones de Pareja (36\%), Sexo (21\%), Ruptura (20\%), Ambiente (9\%) y Sexualidad (4\%).

Las descripciones de mujeres están presentes mayoritariamente en las canciones interpretadas por varones ( $26.77 \%$ de los textos codificados) y en las de interpretación mixtas (24.45\%), mientras que solamente en el $7.88 \%$ de los textos de las canciones interpretadas por mujeres. Las canciones de reggaetón hacen alusión a las mujeres de muchas maneras, desde aquellas que proponen alusiones directas a sus atributos físicos, pasando por descripciones más complejas de modelos femeninos, por ejemplo, maneras de actuar, y hasta maneras degradantes de referirse a ella. Un detalle de las expresiones y formas de describir a la mujer se encuentra en la tabla $8^{2}$.

Tabla 8: Porcentaje de cobertura del tema «Descripciones de la mujer» dentro del texto codificado en las 3 fuentes

\begin{tabular}{|c|c|c|c|c|}
\hline TEMA & Sub categoría & Mujeres & Hombres & Mixto \\
\hline \multirow{2}{*}{$\begin{array}{l}\text { Mujer definida por } \\
\text { atributos }\end{array}$} & $\begin{array}{l}\text { Referencias a atributos físicos } \\
\text { femeninos }\end{array}$ & 1.31 & 2.42 & 8.89 \\
\hline & Referencias a otros atributos & - & 0.37 & - \\
\hline \multirow{7}{*}{$\begin{array}{l}\text { Modelos } \\
\text { femeninos } \\
\text { propuestos }\end{array}$} & Preferida/única & - & 2.08 & 1.13 \\
\hline & Libertina/seductora & 1.61 & 5.22 & 7.43 \\
\hline & Liberada del hombre & 4.21 & 2.71 & 0.70 \\
\hline & Doble cara & 0.75 & 1.83 & 0.81 \\
\hline & Mala & - & 4.43 & 0.29 \\
\hline & Hecha la difícil & - & 3.52 & - \\
\hline & Poderosa & - & 3.03 & 3.95 \\
\hline
\end{tabular}

2. Por razón de espacio, no se identifican las piezas citadas de donde surgen algunos de los fragmentos, salvo cuando el fragmento es extenso.

Feminismo/s 35, junio 2020, pp. 291-320 
Dime lo que escuchas y te diré quién eres. Representaciones de la mujer en las 100 canciones de reggaetón más populares en 2018

\begin{tabular}{|l|l|c|c|c|}
\hline \multirow{4}{*}{$\begin{array}{l}\text { Degradación de } \\
\text { la mujer: mujer } \\
\text { deshumanizada }\end{array}$} & Animal & - & 0.29 & - \\
\cline { 2 - 5 } mujer parcial & Diablo & - & 0.54 & - \\
\cline { 2 - 5 } & Partes anatómicas & - & 0.15 & 0.14 \\
\cline { 2 - 5 } & Puta & - & 0.18 & 1.11 \\
\cline { 2 - 5 } & TOTAL & 7.88 & 26.77 & 24.45 \\
\hline
\end{tabular}

Fuente: elaboración propia (2019)

En cuanto a las descripciones sencillas, los atributos físicos son los más cantados de la mujer en todas las fuentes ( $4.2 \%$ en promedio), con innumerables referencias al cuerpo total; los hombres celebran el cuerpo femenino («ese cuerpo me tiene sudando» "estás bien dura») y a la mujer bonita («mujer tan bella») y las mujeres también se autodefinen por ello: "estaba bonita» «todo el mundo loco con mi cinturita». La posibilidad de cirugías es citada en el reggaetón masculino ( "no hay cirugía, ella nació bien completa» «y le pregunté que cual cirujano era ese/me dijo que se operó en $\mathrm{RD} /$ me dijo que siempre quiso ser doble D/ y que el culo no se lo ha hecho»). Estas consideraciones priman sobre las referencias a otros atributos hechas por los varones, como por ejemplo "sencilla», "con esa sensualidad y esa actitud», "toda una dulzura», las que representan solamente el $0.37 \%$.

Entre las descripciones ligadas a modelos femeninos, algunas se presentan como aparentemente valorativas de la mujer. Para mejor ilustración, en las siguientes citas, entre paréntesis se indica la fuente en siglas: reggaetón cantado por hombres (RH), reggaetón cantado por mujeres (RF), y reggaetón mixto (RM).

- Preferida/ única: la mujer escogida por el varón entre varias para ser la receptora de su atención, y que se valora por características especiales, muchas veces la sexual: «es que me gustas tú nada más/no importan las demás» (RH), «es única y solo yo se lo puedo ver» (RH), «tú eres mi baby personal, pegadita, exclusive» (RH).

- Libertina/ seductora: mujer a la que le gusta divertirse y tiene un apetito sexual que necesita ser satisfecho. Los hombres cantan: «la veo en la disco casi todos los weekends/ al parecer en su casa no hay quien la frenelel vacilón de ella comienza desde el jueves» (RH), «es una loca» (RH), «me dijo que quería prender que le llegara/ le llegué y

Feminismo/s 35, junio 2020, pp. 291-320 
se me tiró encima para que la besara» (RH); y las mujeres contestan de la misma manera: «que no se te apague la excitación/tú sabes que yo no te dejo plantado» (RF).

- Liberada del hombre: mujer que decide por su propio destino, que prefiere estar sola y vivir con sus reglas, generalmente después de una decepción amorosa. Los hombres dicen: "Ya está solteral y no espera quien la quiera/ no se mete con cualquiera/ solo con el que ella quiera»(RH), "y todos quieren con ella/ y ella con nadie quiere nada/ porque prefiere estar sola/que mal acompañada» (RH); Las mujeres también se autodefinen así: «de nadie me dejo» (RM), «soy una reina y su destino controla» (RF).

Los otros modelos transmitidos en las canciones presentan claramente a la mujer en sus aspectos negativos: doble cara, mala, hecha la difícil y poderosa.

- Doble cara: este modelo se encuentra en descripciones de la mujer en que esta presenta una actitud aparentemente tranquila pero en el fondo es otra; generalmente, esta doble actitud se refiere a lo sexual. Los hombres del reggaetón cantan que la mujer es: «santa de día, diabla cuando cae la luna» (RH), "ella es decente, pero solo en el díal porque la noche calma las ganas que tenía» (RH), "y tú eres buena pero por dentro tienes tanta maldad», "carita de inocente pero eres bien pervertida» (RH); "no te hagas la santa que tú sabes que tú quieres/ que yo te toque ahì (RM). Al contestar en el reggaetón femenino, la mujer le dice que tiene razón: "siempre he sido una dama/ pero soy una perra en la cama» (RM).

- Mala: se describe en las canciones a una mujer llena de sentimientos negativos, que busca hacer daño al varón: «eres una asesina, un diablo en cuerpo de mujer» (RH), «mala mujer» (RH), «traicionera, no me importa lo que tú me quieras» (RH). La mujer usa al varón ( «tú eres una hipócrita/ un día me amas y otro día me odias» (RH), «mami, tú muy mal me trataste/usaste, tú me utilizaste/ solo te importaba el dinero» $(\mathrm{RH})$ ), maltrata su corazón ( «mi corazón lo maltratastel conmigo en verdad te pasaste/ mataste mi hombría y en un par de días las manos te las ensuciaste»). Llega a ser "más mala que Anabelle» (RM), "te deja marcado como el Zorro» (RM). 
- Hecha la difícil: es un tipo de mujer descrita sólo en el reggaetón de varones, que no cede al deseo masculino inmediatamente, lo tiene esperando, lo ignora, es orgullosa: «solo me buscas cada vez que te conviene/ se pone difícil, su orgullo no hay quien lo frene», "bebé, deja el orgullo», "me mata que tú siempre me trates así/ te haces la difícil». Y el varón no entiende por qué no cede: «por darte tanto puesto es que ya no te cojo en serio/ haciéndote la difícil, pero ¿por qué?».

- Poderosa: describe a la mujer como dotada de poderes, que logra hacer que el varón realice acciones en contra de su voluntad y que escapan de su control: « es una niña de desconocida criatura/de noche ella empaña tu visión/ con solamente mirarla/de magia negra ella me llama/ tiene algo que hipnotiza mamá/ me hechiza» (RH), y usando sus atributos «jugando con mi mente eres experta/entre esas piernas tú tienes poderes» (RH), "hechicera, tú me embrujas cada vez que tú me hablas» (RH), o dándole algo «me tienes enviciado con eso que me has dado» (RH). La mujer le ratifica esto: "Cuidao, porque te vas envolver/ Cuidao, las mujeres tienen poder/ Cuidado, aviso de peligro» (RM)

Finalmente, está la degradación de la mujer, a través de un tratamiento peyorativo en las descripciones en las cuales se ha sustituido la palabra mujer, y los varones usan como sinónimo, directamente, referencias a animales («las gatas son de tres en tres»), al diablo ( hija del diablo», "hija de Lucifer»), partes anatómicas ( «tengo un culo en cada país», «me voy a tirar un par de traseros»), o la palabra "puta» («tengo otras putas nuevas en el menú», "sata en todas las poses»). Cabe recalcar que estas descripciones están ausentes en el reggaetón femenino.

En la figura 1 se ilustra la presencia de las diferentes categorías de descripción en las fuentes y cómo algunas de ellas son compartidas. Al compararlas se encontró que:

1. No existe una categoría exclusiva de autodescripción de las mujeres en sus canciones.

2. Los modelos femeninos con los cuales están de acuerdo las mujeres, presentes en el reggaetón de varones y mixto pero también en el reggaetón exclusivamente femenino, son: libertina/seductora, liberada 
Dime lo que escuchas y te diré quién eres. Representaciones de la mujer en las 100 canciones de reggaetón más populares en 2018

del hombre y doble cara, así como las descripciones por sus atributos físicos.

3. Los modelos femeninos que avalan las mujeres, al cantar con varones en el reggaetón mixto son: la preferida/única, la mala, la poderosa, y aceptan que se las trate de manera degradante como putas y como una parte anatómica.

4. Los modelos que no son compartidos por las mujeres, ni están presentes en el reggaetón mixto y son entonces exclusivos de varones son: la hecha la difícil, las imágenes degradantes como animal o diablo y las referencias a otros atributos femeninos positivos.

Figura 1: Descripciones de la mujer relatadas según cada una de las fuentes

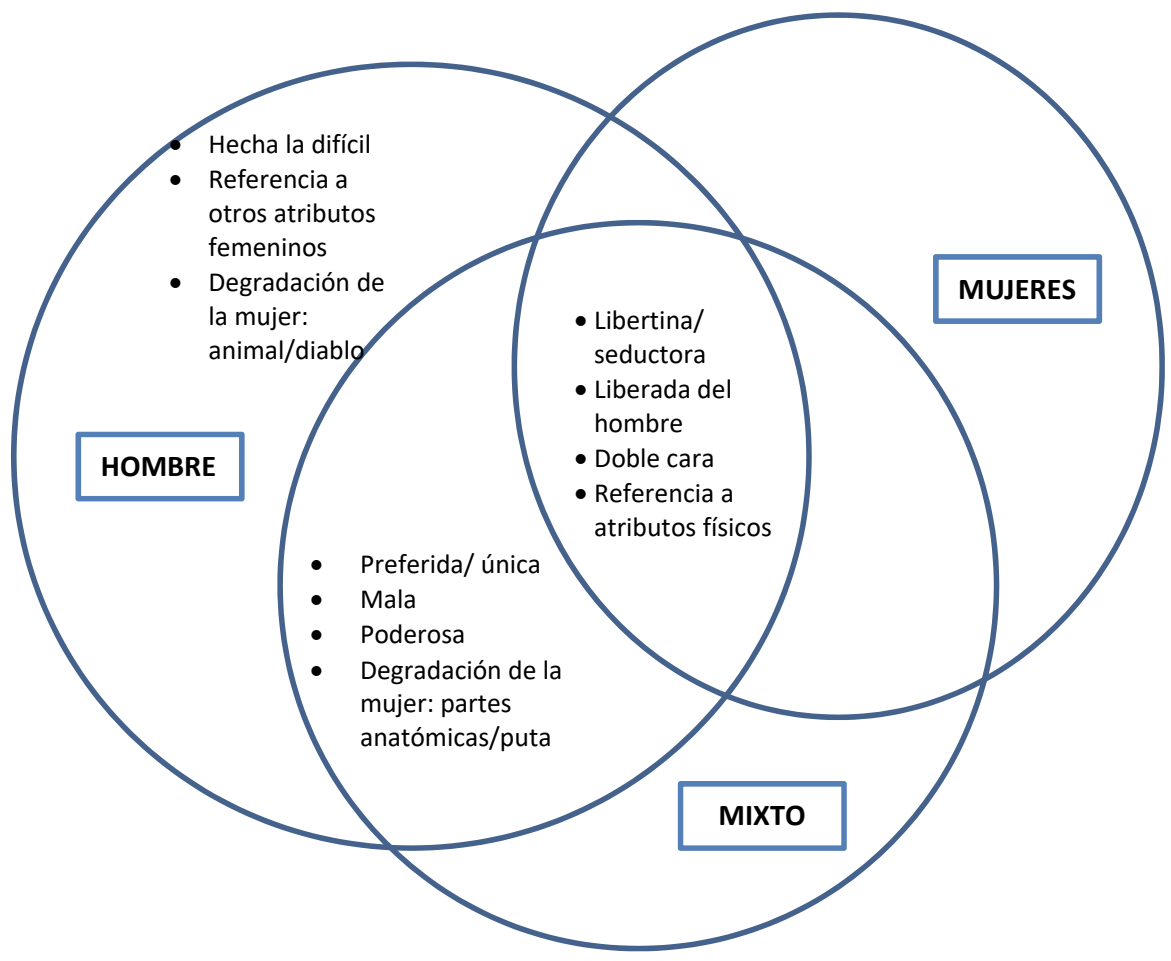

Fuente: elaboración propia (2019)

Feminismo/s 35, junio 2020, pp. 291-320 


\subsection{Representación femenina dentro del género: presencia e imagen como intérpretes y compositoras}

En el análisis realizado, solo 4 canciones son de intérpretes femeninas, lo que deja entrever que el espacio del reggaetón es casi exclusivamente masculino. Si sumamos las canciones mixtas, tenemos que sólo el 14\% del reggaetón popular en 2018 incluyó a mujeres como intérpretes o cointérpretes. El fenómeno se extiende a la composición de las canciones: en el análisis realizado, $79 \%$ son compuestas exclusivamente por hombres y en $17 \%$ se incluye a una o dos mujeres máximo en la composición (en el 4\% la autoría es corporativa); no se encontró ninguna canción analizada de autoría exclusivamente femenina, lo que muestra que la presencia de las mujeres es minoritaria en este plano también.

Lo representado en los vídeos de las cantantes femeninas no difiere de los vídeos de reggaetón mixto y masculino (tabla 9).

Así, las intérpretes femeninas, protagonistas además en sus vídeos, se presentan bailando provocativamente o perreando, en ropa corta o pegada o incluso en ropa interior, permitiendo en ellas mismas los enfoques de cámara en nalgas, senos o pelvis, totalmente sexualizadas (provocativas, acariciándose lascivamente, interactuando entre ellas sexualizadamente), en ambientes de diversión, íntimos o sexuales.

$\mathrm{Al}$ analizar las temáticas generales de estas cuatro canciones, lo que sobresale en los temas son narraciones relacionales, que se encuentran detallados en la tabla 10 . 
Dime lo que escuchas y te diré quién eres. Representaciones de la mujer en las 100 canciones de reggaetón más populares en 2018

Tabla 9: Categorías de análisis de las cuatro canciones de reggaetón interpretadas por mujeres que se incluyeron en este estudio

\begin{tabular}{|c|c|c|}
\hline Categoría & Subcategoría & $\begin{array}{l}\text { Número } \\
\text { de } \\
\text { vídeos }\end{array}$ \\
\hline \multirow{4}{*}{ Tipo de baile } & Baile provocador & 4 \\
\hline & Perreo & 2 \\
\hline & Perreo «duro» o marroneo & 1 \\
\hline & Perreo en grupo o baile grupal & 1 \\
\hline \multirow{2}{*}{$\begin{array}{l}\text { Presentación de } \\
\text { las mujeres }\end{array}$} & Mujer en ropa corta o pegada & 4 \\
\hline & Mujer en ropa interior & 4 \\
\hline \multirow{3}{*}{ Objetivación } & Mujer fragmentada & 3 \\
\hline & Mujer ornamental & 2 \\
\hline & Mujer no objetivada & 0 \\
\hline \multirow{4}{*}{$\begin{array}{l}\text { Mujer } \\
\text { sexualizada }\end{array}$} & Mujer provocativa & 4 \\
\hline & Mujer lasciva & 4 \\
\hline & Mujer del goce & 2 \\
\hline & Mujer no sexualizada & 0 \\
\hline \multirow{3}{*}{ Tipo de ambiente } & Sexualizados & 4 \\
\hline & No sexualizados & 0 \\
\hline & Otros & 1 \\
\hline $\begin{array}{l}\text { Sexualización del } \\
\text { ambiente }\end{array}$ & $\begin{array}{l}\text { Imitación de posturas, escenas } \\
\text { íntimas }\end{array}$ & 1 \\
\hline \multirow{2}{*}{$\begin{array}{l}\text { Consumo de } \\
\text { sustancias }\end{array}$} & Alcohol & 3 \\
\hline & No consumo & 1 \\
\hline
\end{tabular}

Fuente: elaboración propia (2019)

Feminismo/s 35, junio 2020, pp. 291-320 
Dime lo que escuchas y te diré quién eres. Representaciones de la mujer en las 100 canciones de reggaetón más populares en 2018

Tabla 10: Temáticas de las 4 canciones de reggaetón femenino analizadas

\begin{tabular}{|c|c|c|c|}
\hline $\begin{array}{l}\text { Nombre de } \\
\text { la canción e } \\
\text { intérpretes }\end{array}$ & $\begin{array}{l}\text { Temática } \\
\text { narrada }\end{array}$ & Cita de la canción & Compositores \\
\hline $\begin{array}{l}\text { «Sin } \\
\text { Pijama» } \\
\text { - Becky } \\
\text { G, Natti } \\
\text { Natasha }\end{array}$ & $\begin{array}{l}\text { Narración de } \\
\text { sexo y diversión } \\
\text { bajo pedido del } \\
\text { varón }\end{array}$ & $\begin{array}{l}\text { Si tú me llamas/ Nos vamo' pa' tu } \\
\text { casa/ Nos quedamo' en la cama, Sin } \\
\text { pijama, sin pijama/ Voy pa' contarle } \\
\text { mis secretos a tu almohada/ Mientras } \\
\text { tanto hagamos vídeo llamada/ Me } \\
\text { manda foto', fotico'/Mostrando todo, } \\
\text { todito/ Cuando llegue desbaratamo' } \\
\text { la cama» }\end{array}$ & $\begin{array}{l}\text { Cinco } \\
\text { hombres, } \\
\text { una mujer }\end{array}$ \\
\hline $\begin{array}{l}\text { «No me } \\
\text { acuerdo» } \\
\text { - Thalía, } \\
\text { Natti } \\
\text { Natasha }\end{array}$ & $\begin{array}{l}\text { Narra una salida } \\
\text { a una fiesta; la } \\
\text { protagonista al } \\
\text { día siguiente no } \\
\text { recuerda nada } \\
\text { por consumir } \\
\text { alcohol. } \\
\text { Admite posible } \\
\text { infidelidad, } \\
\text { avalando } \\
\text { fantasía } \\
\text { masculina }\end{array}$ & $\begin{array}{l}\text { "Para mí tan solo hay uno/ Pero si } \\
\text { te hace feliz/ Saber que estuve con } \\
\text { otro/ Vamos a decir que sí/ Pero no me } \\
\text { acuerdo, no me acuerdo/ Y si no me } \\
\text { acuerdo, no pasó». }\end{array}$ & $\begin{array}{l}\text { Cinco } \\
\text { hombres, } \\
\text { una mujer }\end{array}$ \\
\hline $\begin{array}{l}\text { «Mi cama» } \\
\text { - Carol G }\end{array}$ & $\begin{array}{l}\text { Narración } \\
\text { de despecho } \\
\text { sentimental, } \\
\text { en donde la } \\
\text { recuperación se } \\
\text { transforma en } \\
\text { revanchismo y } \\
\text { la protagonista } \\
\text { pasa a ser } \\
\text { promiscua } \\
\end{array}$ & $\begin{array}{l}\text { «Piensas que yo me quedé tranquila/ } \\
\text { Y los tengo haciendo fila/ Mientras } \\
\text { que tu inventas dar pom pom pom } \\
\text { pom/ Mi cama suena y suena/ Mi } \\
\text { cama suena y suena». }\end{array}$ & $\begin{array}{l}\text { Cuatro } \\
\text { hombres, } \\
\text { una mujer }\end{array}$ \\
\hline $\begin{array}{l}\text { «acuzzi» } \\
\text { - Greeicy, } \\
\text { Anitta }\end{array}$ & $\begin{array}{l}\text { Narración } \\
\text { del primer } \\
\text { encuentro entre } \\
\text { la protagonista } \\
\text { y un hombre, } \\
\text { que termina en } \\
\text { sexo. }\end{array}$ & $\begin{array}{l}\text { «Sólo un par de copas y se me prendió } \\
\text { en deseo/ Todo comenzó en la barral } \\
\text { Cuando apagaron la' luces/ Nos } \\
\text { miramos por un rato/Y así fue que le } \\
\text { propuse/ Yo tengo vino en la casa/ Y } \\
\text { ya va llegando el Uber/ Y dijo vamo' } \\
\text { a ver qué pasa/ Y terminamo' en el } \\
\text { jacuzzi». }\end{array}$ & $\begin{array}{l}\text { Cinco } \\
\text { hombres, } \\
\text { una mujer }\end{array}$ \\
\hline
\end{tabular}

Fuente: elaboración propia (2019)

Feminismo/s 35, junio 2020, pp. 291-320 
Además, se puede observar que las cuatro canciones son compuestas esencialmente por autores varones, lo que en realidad no difiere de lo que sucede en el género en general. En el análisis realizado con la información disponible en la internet sobre los compositores, se observa que cada canción tiene múltiples autores, sin especificar si han intervenido en la composición musical, de las letras o ambas; sin embargo, se ha contabilizado que de los 247 compositores involucrados en las canciones, sólo catorce son mujeres (5.67\%).

\section{DISCUSIÓN}

Al analizar las 100 canciones más populares de reggaetón en 2018 con parámetros claros de inclusión, se evitaron posibles sesgos que pueden introducirse al «escoger» las más representativas de un género. Estableciendo criterios, una ventana temporal amplia (un año) y seleccionando una muestra extensa, se obtuvo un panorama más exacto y objetivo del tema analizado. El estudio realizado tanto de vídeos como de letras e intérpretes/compositores permite que las afirmaciones que se hacen sobre los contenidos tengan un soporte documentado y sólido, evitando críticas como las de Gallucci (84) que sostiene que las afirmaciones que normalmente se hacen sobre el tema no tienen sustento al no analizar realmente los textos.

Si bien se afirma que el reggaetón es un espacio en donde las mujeres están representadas, en este estudio se encuentra evidencia de que esto no ocurre, considerando que en la muestra el $86 \%$ de las canciones más escuchadas son cantadas por hombres, un $10 \%$ son mixtas y solamente el $4 \%$ son interpretadas por mujeres, y que la presencia femenina es minoritaria en la composición de estas canciones (5.67\%). Estos porcentajes claramente ilustran la diminuta representación de las mujeres en el género, ya que aunque las mujeres están presentes en los vídeos y letras, su papel no es protagónico.

El análisis de las letras indica que la mujer es descrita en sus roles de género tradicionales. Es la mujer pasiva, como vemos en las descripciones de la preferida/única, que adquiere valor por la mirada del hombre, o la liberada del hombre que se descubre libre después de una relación nociva, dejando de manifiesto que la mujer no puede ser autónomamente libre sino lo hace momentáneamente y por revanchismo. El modelo valorativo de libertina/ seductora plantea una mujer definida por su sexualidad, espacio que la 
empodera frente al hombre, pero que la sigue definiendo en relación a él, ya que es una sexualidad para ser vista por los hombres y provocativa para ellos; en definitiva, es un «ser-para-los-hombres» (De Toro 90).

Por otro lado, se describen mujeres con actitudes de supremacía. Así, en las canciones analizadas se percibe que la mujer es dicótoma (doble cara), que tiene intenciones ocultas y malvadas (mala), que el vincularse a ella o sentir algo por ella no depende del hombre sino es un ejercicio de poder sobre él (poderosa), y que cuando no cede a sus deseos no es por un desinterés legítimo hacia él sino por hecha la difícil.

En estos discursos existe una reproducción de lo tradicional. Lo que denominamos doble cara es lo que De Toro (91) señala como dicotomía « ¿Ser virgen o ser perra? ¿Ser dulce o gata?». Sin embargo, esta dicotomía es solo aparente puesto que las mujeres intérpretes han tomado ya postura, escogiendo el rol de perras para la intimidad: «siempre he sido una dama pero soy una perra en la cama». Por otro lado, las categorías de hecha la difícil, poderosa y mala corresponden a interpretaciones de la conducta femenina que cuando no se pliega al deseo masculino, ejerce autonomía o voluntad propia, es juzgada por el varón negativamente, como manipulándolo a través del cuerpo o intentando doblegar su voluntad, algo que ha sido subrayado ya por estudios anteriores (Fonseca 103-104). Estas adjetivaciones sobre la mujer no solo se encuentran en la boca del hombre para hablar de ella, sino que la mujer también ya las ha hecho suyas.

En este estudio, la objetivación de la mujer se presenta tanto a nivel de los vídeos como de las letras. La mujer es representada como un adorno del varón, en sobrenúmero en los vídeos, lo que la vuelve anónima y reemplazable: no importa quién está, lo que importa es que estén y que sean bastantes. Adicionalmente, el cuerpo de la mujer se fragmenta en las tomas de cámara, ya que la reducen a un «trozo de mujer» (unas nalgas, unos senos), haciendo lo mismo en las letras al emplear partes anatómicas en reemplazo de la palabra mujer ("a los culos que traigan su cuero»). La mujer en el reggaetón es, así mismo, deshumanizada, al compararla con el diablo o al animalizarla.

Por otro lado, la sexualización de la mujer en el espacio del reggaetón es evidente: se la describe por sus atributos físicos, que son los que la representan, estos atributos se exhiben en los vídeos de hombres y mujeres, las intérpretes femeninas esculpen sus cuerpos para mostrarlos en ropa interior

Feminismo/s 35, junio 2020, pp. 291-320 
o corta. Es evidente cómo las intérpretes a través de sus propios cuerpos representan el modelo femenino estereotipado: cuerpos esculturales, senos y nalgas grandes y perfectos. Todas las intérpretes han pasado por cirugías, y algunas hablan abiertamente de ello: «No quiero que la gente de casa quede mirando a las portadas y hablando '¿por qué no soy así? Y ¡qué vida injusta!' No, solo trabaje, junte su dinero y va a quedar como quiera» (Restrepo). El cuerpo tiene valor en la imagen «siempre cuando sea bello y joven» "y este se representa como un producto social para ser deseado, exhibido, gozado y violentado» (De Toro 94). La sexualización está en el discurso del hombre al describir a la mujer, y en el de la mujer al autodescribirse, asumiendo ambos que el cuerpo sexuado es la parte principal de la identidad desde la cual y sobre la cual comunicar y relacionarse con el otro. La mujer «es objeto de deseo sexual [...] en la medida en que sus atributos físicos siguen siendo el principal requisito para generar una relación afectiva y vinculación con el mundo masculino» (Fonseca 101-102).

Los resultados de este estudio indican que la imagen de «emprendedora sexual» se transmite también en la canciones de reggaetón. Los análisis muestran a una mujer apropiada de un modelo sexualizado, apropiación que se evidencia al mostrar el cuerpo en los vídeos, al perrear, al cantar junto con los intérpretes masculinos canciones que transmiten los mismos modelos, al autodefinirse de la misma manera que las definen los hombres, con un mismo discurso, sin generar nueva categorías descriptivas, sin presentar otros cuerpos, otras maneras de vestirse, otros contenidos que no sean los sexuales y relacionales estereotipados en las canciones. Es de crucial importancia subrayar que esta autobjetivación, según algunos autores, en lugar de empoderar a las mujeres transmite el mensaje de que para el género femenino la única manera de tener éxito en la industria musical es a través de la objetivación de sí mismas (Aubrey y Frisby 496).

Los autores de este estudio concordamos con esta visión y sostenemos que los resultados del análisis muestran que la supuesta «resistencia femenina» en el reggaetón no existe. Lo que es manifiesto en este tipo de música es una propuesta de un modelo de mujer que responde a una estética particular, a una conducta estereotipada, sexualizada, disponible, ligera, que le gusta divertirse. Además, según el hombre del reggaetón, la mujer es poco auténtica con su verdadera naturaleza (la sexual), potencialmente mala y peligrosa, y él

Feminismo/s 35, junio 2020, pp. 291-320 
cede solo en contra de su voluntad. La mujer, en lugar de resistir, toma estas identificaciones y las hace suyas, creyendo «empoderarse» a través de ello, cuando en realidad se moldea a la sugerencia masculina, a sus reglas, límites, conductas y propuestas de relacionamiento; tal como dicen Rodríguez-López y Caldeiro-Pedreira, las mujeres «recogen actitudes tradicionalmente atribuidas a la masculinidad [...] en lugar de crear actitudes propias» (77).

\section{CONCLUSIONES}

En suma, el reggaetón es un espacio esencialmente masculino, en donde lo que se canta, se crea y se transmite representa la visión de un varón sobre lo que es la mujer, independientemente del género del intérprete.

El reggaetón, sin embargo, no es responsable de generar el modelo de mujer sexualizada y objetivada; solo hace lo que otros productos culturales como la publicidad, el cine y otros géneros musicales hacen, transmiten y refuerzan. Las canciones producidas actualmente en el género del reggaetón y que son populares, perpetúan los modelos que obedecen a las leyes del mercado. Como lo subraya Ramos (72) «La música, además de ser una forma de arte, es una industria y un mercado con el objetivo principal de obtener un beneficio»; lo que se vende es lo que se compra y viceversa. La industria de la música es un negocio, que genera miles de millones de dólares y que inculca en audiencias mundiales ideologías dominantes de raza, clase, género, sexualidad y nacionalidad (Hobson y Bartlow, en Ramos 73). Los vídeos que acompañan a las canciones también obedecen a una lógica de mercado: «su objetivo es ayudar a vender una canción y por ello deben recrear un mundo apetecible para el oyente/consumidor deseado» (Guarinos 307).

La representación de la mujer en este género musical es solamente un ejemplo de un fenómeno más amplio que se observa en el mundo del espectáculo, que en las últimas décadas se ha teñido más y más de contenidos sexuales y objetivantes de la mujer. Según Feinman (589-590), estamos en una época en la cual los medios de comunicación ejercen poder sobre el individuo a través del entretenimiento, centrado cada vez más en lo sexual. El género del reggaetón y su popularización entran a formar parte de este juego de sometimiento moderno. 
Los modelos femeninos propuestos por la sociedad posmoderna (y dentro de ellos, los del reggaetón) son incorporados dentro del proceso de construcción de la identidad de las mujeres a través de los mecanismos de identificación. Estos modelos además convergen desde diferentes fuentes hacia uno que los engloba: la mujer del disfrute; la sociedad lo propone y las mujeres construyen identidades del disfrute a través de este modelo, transformándose en mujeres para ser disfrutadas y que tienen que disfrutar el hecho de serlo. En palabras de Guarinos (312): «La mujer sexualizada es un estereotipo pero también un prototipo propuesto por las propias cantantes mujeres para consumidores hombres y que sirven de modelo imitable para consumidoras mujeres».

En conclusión, la nueva imagen femenina no solo construye un ideal del cuerpo, de las actitudes y de la vida sexual de la mujer, sino que transforma internamente a la mujer a través de una subjetivización de su cuerpo, de sus actitudes y hasta de su sexualidad. De todas las consecuencias de la música sexualizada (TFSPM 3-4), en los resultados este estudio se evidencian la autosexualización y autovalidación de la mujer por su imagen física; procesos que van a afectarla durante toda su vida, puesto que se construye internamente y se define externamente con los modelos propuestos, apropiándose de ellos en su cuerpo e imaginario, es decir «convirtiéndose» en lo que la sociedad le va dando como modelo normativo.

La evidencia científica disponible al respecto y reseñada en el informe de la TFSPM (17) apunta a que existe un impacto negativo ya que las mujeres «llegan a percibirse a sí mismas en función de cómo creen que sus cuerpos se parecen a los demás y, por lo tanto, se centran en sus rasgos perceptibles externamente en lugar de sus rasgos internos» (Fredrickson y Roberts, en TFSPM 17). Las consecuencias de esta autobjetivación son dañinas para ellas: sentimientos de vergüenza y ansiedad, incapacidad para experimentar los estados motivacionales y una desconexión entre los cuerpos externos de las personas y sus propias experiencias corporales internas (TFSPM 17).

Con estos antecedentes, y basándonos en lo analizado, concluímos que el reggaetón popular e importado al Ecuador presenta modelos estereotipados de la mujer, a través de sus letras, vídeos y de la imagen de las mujeres intérpretes. La evidencia científica constata que la exposición a cualquier tipo de música sexualizada afecta negativamente a las personas. Se debe resaltar

Feminismo/s 35, junio 2020, pp. 291-320 
Dime lo que escuchas y te diré quién eres. Representaciones de la mujer en las 100 canciones de reggaetón más populares en 2018

el impacto negativo que estos modelos tienen en la construcción interna de las mujeres.

En definitiva, los resultados de este estudio cuestionan seriamente otras posturas (personales, experienciales, de las artistas del reggaetón y de las activistas feministas), que proponen la música sexualizada del reggaetón y su baile como espacios de empoderamiento femenino.

\section{REFERENCIAS BIBLIOGRÁFICAS}

Adams, Terri y Douglas Fuller. "The words have changed but the ideology remains the same. Misoginistic lyrics in rap music». Journal of black studies 36 (2006): 938-957.

Aguilar Barreto, Andrea y Ronal Peñaloza Figueroa. «Reggaetón e identidad sexual: una relación para pensar la política pública en sexualidad». Políticas públicas: desafíos en Colombia y Venezuela. Comps. Modesto Graterol, María Mendoza, Rosemily Graterol, Julio Contreras y John Espinosa. Maracaibo: Universidad del Zulia, 2017. 101-128.

Alcaraz, María. «Fanáticas de mover el culo: twerking y feminismo». Latfem, 2017. Web. 19 marzo 2019.

Aubrey, Jennifer y Cynthia Frisby. «Sexual Objectification in Music Videos: A content analysis comparing gender and genre». Mass communication and society 14 (2011): 475-501.

Braun, Virginia y Victoria Clarke. «Using thematic analysis in psychology». Qualitative research in psychology 3 (2006): 77-101.

Dávila, Verónica. «Acelerando la feminidad en el reggaetón: La chapa que vibra de La Materialista». Perspectives on Reggaeton. Eds. Vigimaris Nadal-Ramos y Dorsía Smith Silva. Puerto Rico: University of Puerto Rico, 2016. 59-66.

De Toro, Ximena. «Métele con candela pa'que todas las gatas se muevan. Identidades de género, cuerpo y sexualidad en el reggaetón». Revista Punto Género 1 (2011): 81-102.

Feinman, José. Filosofía Política del Poder Mediático. Buenos Aires: Planeta, 2013. Feliciano, Omar. «Perrea un feminismo». Animal Político, 2015. 13 enero 2020.

Fonseca, Clara. Dale mi loba que tú eres la killa. Análisis de las marcas valorativas de la imagen femenina en el reggaetón. Diss. Universidad de Cartagena, 2010. Gallucci, María. «Análisis de la imagen de la mujer en el discurso del reggaetón». Opción 55 (2008): 84-100. 
Dime lo que escuchas y te diré quién eres. Representaciones de la mujer en las 100 canciones de reggaetón más populares en 2018

Guarinos, Virginia. «Estereotipos y nuevos perfiles de mujer en la canción de consumo, de la romántica a la mujer fálica». Cuestiones de género: de la igualdad $y$ de la diferencia 7 (2012): 297-314.

Hall, P.Cougar, Joshua West y Shane Hill. «Sexualization in lyrics of popular music from 1959 to 2009: Implications for sexuality educators». Sexuality $\mathcal{E}$ Culture: An interdisciplinary Quaterly 16.2 (2012): 103-117.

Harvey, Laura y Rosalind Hill. «Spicing it up: sexual entrepreneurship and the sex inspectors». New Femininities: Postfeminism, Neoliberalism and Subjectivity Eds. Rosalind Gill \& Christina Scharff. London \& New York: Palgrave, 2011. 52-67.

Horkheimer, Max y Theodor Adorno. Dialéctica de la Ilustración. Fragmentos filosóficos. Madrid: Editorial Trotta, 1998.

Martínez Noriega, Dulce. «Cultura, música y juventud: una reflexión acerca del reggaetón como fenómeno cultural». Cinzontle 7.16 (2015): 18-24.

Negrón-Muntaner, Frances y Raquel Rivera. «Nación Reggaetón». Nueva Sociedad 223 (2009): 29-38.

Noisey Colombia. "El culo como territorio político: asistimos a uno de los Twerkshops de Fannie Sosa». Vice, 2015. Web. 19 marzo 2019.

Pérez-Rufí, José. «Mujeres en el videoclip: la representación de la mujer en los vídeos musicales de Diane Martel». Prisma social n. ${ }^{\circ}$ especial 2 (2017): 202-232.

Ramos, Isabel. "'A ella le gusta agresivo': An analysis of the negative representation of women in reggaeton songs». Social Eyes 6 (2015): 67-75.

Redacción El Comercio. "Estas fueron las canciones más escuchadas en Ecuador en el 2018». El Comercio, 2018. Web. 13 enero 2020.

Restrepo, Wendy.«No niega sus cirugías, así se veía Anitta antes de pasar por el quirófano». Colombian, 30 de Octubre 2018.

Rivera, Raquel. «Perreo \& Power: Explicit Sexuality in Reggaeton Dance». Ponencia presentada en la Conferencia de la Asociación de Estudios Latinoamericanos en Río de Janeiro, Brasil, 2009. 19 de marzo 2019. <https://drive.google.com/ file/d/1kq7VpUXmCWGJ7DWRauR02bhcRCU-k84F/view>

Rodríguez-López, Jennifer y Mari Carmen Caldeiro-Pedreira. «Divas clip: la imagen actual de la mujer en el video musical». Temas de comunicación 31 (2015): 59-80.

Rodrigues Morgado, Carolina. «Reggaetón, mujeres e identidades: "yo quiero bailar... eso no quiere decir que pa' la cama voy”». Diss. FLACSO, 2012. 
Rodríguez Rivera, Ángel. «Acumulación subalterna: cultura, clase, raza y reggaetón». Perspectives on Reggaeton. Eds. Vigimaris Nadal-Ramos y Dorsía Smith Silva. Puerto Rico: University of Puerto Rico, 2016. 26-38.

Sedeño, Ana María. «El cuerpo del cantante en los videoclips: una propuesta de análisis textual». Ponencia presentada en el IV Congreso latinoamericano de investigadores de la Comunicación en Santa Cruz de la Sierra, Bolivia, 2002. <https://studylib.es/doc/239614/el-cuerpo-del-cantante-en-los-videoclips>

Sprankle, Eric, Christian End y Miranda Bretz. «Sexually degrading music videos and lyrics». Journal of media psychology 24 (2012): 31-39.

Task Force on the Sexualization of Popular Music. Washington, D.C.: Division 46 (Society for Media Psychology \& Technology) of the American Psychological Association, 2018.

Unidad Editorial Información Deportiva. «Ocho de las diez canciones más escuchadas en YouTube en 2018 fueron en español», 6 de Diciembre 2018.

Vernallis, Carol. «The functions of lyrics in music video». Journal of Popular Music Studies 14 (2002): 11-31. 